\title{
Derivation of a Novel Scoring System Predicting High Platelet Reactivity on Prasugrel in Patients with Coronary Artery Disease
}

\author{
Yuichi Saito ${ }^{1}$, Takeshi Nishi ${ }^{1,2}$, Shinichi Wakabayashi ${ }^{1,3}$, Yuji Ohno ${ }^{1,4}$, Hideki Kitahara ${ }^{1}$, Noritaka Ariyoshi ${ }^{5}$ \\ and Yoshio Kobayashi ${ }^{1}$
}

\author{
${ }^{1}$ Department of Cardiovascular Medicine, Chiba University Graduate School of Medicine, Chiba, Japan \\ ${ }^{2}$ Department of Cardiology, Kawasaki Medical School, Okayama, Japan \\ ${ }^{3}$ Department of Cardiology, Eastern Chiba Medical Center, Chiba, Japan \\ ${ }^{4}$ Department of Cardiovascular Medicine, Narita Red Cross Hospital, Chiba, Japan \\ ${ }^{5}$ Department of Personalized Medicine and Preventive Healthcare Sciences, Graduate School of Medicine, Dentistry and \\ Pharmaceutical Sciences, Okayama University, Okayama, Japan
}

Aims: High platelet reactivity (HPR) has been associated with an increased risk of thrombotic events in patients undergoing percutaneous coronary intervention. HPR has been well examined in patients treated with clopidogrel; however, HPR on prasugrel is poorly investigated.

Methods: Four prospective studies were pooled, in which platelet reactivity on prasugrel was measured using VerifyNow assay; genotyping of CYP2C19 was also performed. Factors associated with HPR on prasugrel were identified using multivariable analysis to develop a risk prediction model.

Results: In total, 180 patients were examined in this study, of whom $51(28 \%)$ had HPR on prasugrel. The multivariable analysis indicated that hypertension, diabetes, hemodialysis, and the number of CYP2C19 loss-offunction (LOF) alleles are significant factors for HPR on prasugrel. These four factors were then incorporated to develop the HHD-GENE score. The receiver operating characteristic curve analysis showed that the HHDGENE score predicted HPR on prasugrel (area under the curve (AUC) 0.74 , best cutoff value $5, p<0.001$ ). With the best cutoff value, patients with the HHD-GENE score $\geq 5$ had a significantly increased risk of HPR on prasugrel than their counterpart $(50 \%$ vs. $18 \%, p<0.001)$.

Conclusions: The HHD-GENE score consisting of hypertension, diabetes, hemodialysis, and CYP2C19 LOF alleles may be useful in identifying patients on prasugrel who are at high risk for HPR. External validation is needed to define the clinical utility of this novel scoring system.

Key words: Prasugrel, High platelet reactivity, Risk factors

\section{Introduction}

Dual antiplatelet therapy (DAPT) consisting of aspirin and a P2Y12 inhibitor has been the standard of care for patients presenting with acute coronary syndrome (ACS) and undergoing percutaneous coronary intervention (PCI) to reduce subsequent thrombotic events ${ }^{1,2)}$. Current choice of oral P2Y12 inhibitor includes clopidogrel, prasugrel, and ticagrelor ${ }^{3)}$. Clopidogrel is a conventional but still broadly used P2Y12 inhibitor in PCI, whereas prasugrel and ticagrelor are the newer guidelinerecommended agents in patients with ACS ${ }^{1)}$. According to the randomized ISAR-REACT 5 trial results ${ }^{4}$, the recent European guidelines recommend prasugrel in preference to ticagrelor for patients with non-ST segment elevation $\mathrm{ACS}^{5}$.

Inadequate platelet inhibition, namely high platelet reactivity (HPR), has been identified as a predictor of thrombotic events, such as cardiovascular

Address for correspondence: Yuichi Saito, Department of Cardiovascular Medicine, Chiba University Graduate School of Medicine, 1-8-1 Inohana, Chuo-ku, Chiba, Chiba 260-8677, Japan E-mail: saitoyuichi1984@gmail.com

Received: September 30, 2021 Accepted for publication: November 14, 2021

Copyright@2021 Japan Atherosclerosis Society

This article is distributed under the terms of the latest version of CC BY-NC-SA defined by the Creative Commons Attribution License.

\section{Advance Publication Journal of Atherosclerosis and Thrombosis}


death, myocardial infarction, and stent thrombosis, in patients undergoing $\mathrm{PCI}^{6}$. . It is well known that CYP2C19 loss-of-function (LOF) alleles can reduce the metabolism of clopidogrel, resulting in HPR, but several clinical factors can also contribute to HPR on clopidogrel $^{7)}$. In this context, the recently developed ABCD-GENE score identified one genetic and four clinical factors (age, body mass index, chronic kidney disease [CKD], diabetes, and CYP2C19 LOF allele) for HPR on clopidogrel ${ }^{8)}$. However, a risk prediction model for HPR on prasugrel has not been established. Thus, in this study, we aim to identify the factors associated with HPR on prasugrel to develop a risk scoring system.

\section{Methods}

\section{Study Population and Design}

We have conducted four prospective studies to investigate the effect of P2Y12 inhibitors (clopidogrel and prasugrel) in patients undergoing PCI at Chiba University Hospital (Supplementary Table 1) ${ }^{9-12)}$. Individual patient data were pooled to create the dataset with which we previously validated the ABCD-GENE score in East Asian populations and evaluated the impact of severity of each factor of ABCD-GENE score on HPR on clopidogrel ${ }^{13,}{ }^{14)}$. In this present analysis, factors associated with HPR on prasugrel were investigated to develop a novel scoring system. Study details are described in previous reports ${ }^{13,14)}$. In brief, all patients received aspirin (100 mg daily) as a part of DAPT, and there was no oral anticoagulant. PCI procedures were performed according to the local standards with contemporary drug-eluting stents and intracoronary imaging. ${ }^{15-18}$ Each study included patients with (1) general chronic coronary syndrome ${ }^{9)}$, (2) maintenance hemodialysis ${ }^{10)}$, (3) age $\geq 75$ and/or body weight $<50 \mathrm{~kg}^{11)}$, and (4) $\mathrm{ACS}^{12)}$. Major exclusion criteria are summarized in Supplementary Table 1. All four studies were registered in the University Hospital Medical Information Network and approved by the institutional ethics committee.

\section{Platelet Function Test and CYP2C19 Genotyping}

In the four studies, VerifyNow assay (Accumetrics, San Diego, USA) was used to evaluate on-treatment platelet reactivity to adenosine diphosphate at a maintenance dose of prasugrel $(3.75$ $\mathrm{mg}$ daily). According to the phase II trial in Japan, $3.75 \mathrm{mg}$ of prasugrel daily in Japanese patients is considered to be equivalent to $10 \mathrm{mg}$ daily in Western countries $^{19)}$. VerifyNow P2Y12 platelet reactivity unit (PRU) on prasugrel was measured in all but four patients in the study \#2 (Supplementary Table 1) ${ }^{10)}$. HPR was defined as PRU > 208 based on the recent consensus statement ${ }^{7)}$. Genotyping of CYP2C19*2 (rs4244285, c681G $>\mathrm{A})$ and CYP2C19*3 (rs4986893, c636G $>A$ ) was performed using the GTS-7000 (Shimadzu, Kyoto, Japan) to detect singlenucleotide polymorphisms on direct polymerase chain reaction amplification without DNA extraction. Patients were divided into extensive $\left({ }^{*} 1 /{ }^{*} 1\right)$, intermediate $\left({ }^{*} 1 /^{*} 2\right.$ or $\left.{ }^{*} 1 /^{*} 3\right)$, and poor $\left({ }^{*} 2 /^{*} 2,{ }^{*} 2 /^{*}\right.$ 3 or $\left.* 3 l^{*} 3\right)$ metabolizer groups. The number of CYP2C19 LOS alleles was counted as 0,1 , and 2 in extensive, intermediate, and poor metabolizer, respectively ${ }^{13,14)}$.

\section{Endpoint and Statistical Analysis}

The primary aim of this study was to identify the factors associated with HPR on prasugrel and to develop a risk prediction model. All data are expressed as either mean \pm standard deviation or frequency (\%). Categorical variables were compared using Fisher's exact test. Separate logistic regression analyses were performed to identify the univariable predictors of HPR, presented as odds ratio with 95\% confidence intervals. The potentially associated variables in univariable analyses $(p<0.20)$ were included into the model of multivariable logistic regression analysis. Because CKD defined as estimated glomerular filtration rate $<60 \mathrm{ml} / \mathrm{min} / 1.73 \mathrm{~m}^{2}$ was highly collinear with hemodialysis, the two factors were not included in the multivariable model simultaneously. We then assigned an arbitrary point value based on the odds ratios of the significant factors associated with HPR on multivariable analysis $(p<0.05)$ in order to build a risk prediction model. The receiver operating characteristic (ROC) curve analysis was performed to calculate area under the curve (AUC), based on the presence of HPR on prasugrel. The best cutoff value was established by finding the values that corresponded to the maximum average sensitivity and specificity. The AUC of the ROC curve was compared using DeLong method. As a sensitivity analysis, the ROC analysis for PRU $\geq 262$ was also performed according to the results of phase III trial of prasugrel in Japan ${ }^{20)}$. A $p$-value $<0.05$ was considered statistically significant. Statistical analysis was performed using SAS software version 9.3 (SAS Institute, Cary, USA).

\section{Results}

Of the 180 patients, 51 (28\%) had HPR on prasugrel at a maintenance dose. Table 1 lists the baseline characteristics. More than two-thirds of

\section{Advance Publication Journal of Atherosclerosis and Thrombosis}


Table 1. Baseline characteristics

\begin{tabular}{|c|c|c|c|c|}
\hline Variable & All $(n=180)$ & $\operatorname{HPR}(+)(n=51)$ & $\operatorname{HPR}(-)(n=129)$ & $p$ value \\
\hline Men & $148(82 \%)$ & $41(80 \%)$ & $107(83 \%)$ & 0.67 \\
\hline Hypertension & $135(75 \%)$ & $44(86 \%)$ & $91(71 \%)$ & 0.04 \\
\hline Diabetes & $95(53 \%)$ & $36(71 \%)$ & $59(46 \%)$ & 0.003 \\
\hline Chronic kidney disease & $82(46 \%)$ & $29(57 \%)$ & $53(41 \%)$ & 0.07 \\
\hline Hemodialysis & $33(18 \%)$ & $19(37 \%)$ & $14(11 \%)$ & $<0.001$ \\
\hline \multicolumn{5}{|l|}{ Medications } \\
\hline$\beta$-blocker & $97(54 \%)$ & $28(55 \%)$ & $69(53 \%)$ & 1.00 \\
\hline ACE-I or ARB & $114(63 \%)$ & $31(61 \%)$ & $83(64 \%)$ & 0.73 \\
\hline Proton-pump inhibitor & $140(78 \%)$ & $42(82 \%)$ & $98(76 \%)$ & 0.43 \\
\hline One CYP2C19 LOF allele & $94(52 \%)$ & $28(55 \%)$ & $66(51 \%)$ & 0.74 \\
\hline Two CYP2C19 LOF alleles & $30(17 \%)$ & $11(22 \%)$ & $19(15 \%)$ & 0.27 \\
\hline
\end{tabular}

Patients are divided into two groups according to the presence or absence of HPR on prasugrel. Chronic kidney disease is defined as estimated glomerular filtration rate $<60 \mathrm{ml} / \mathrm{min} / 1.73 \mathrm{~m}^{2}$. ACE-I, angiotensin converting enzyme inhibitor; ARB, angiotensin II receptor blocker; HPR, high platelet reactivity; LOF, loss-of-function.

Table 2. Predictors of HPR on prasugrel

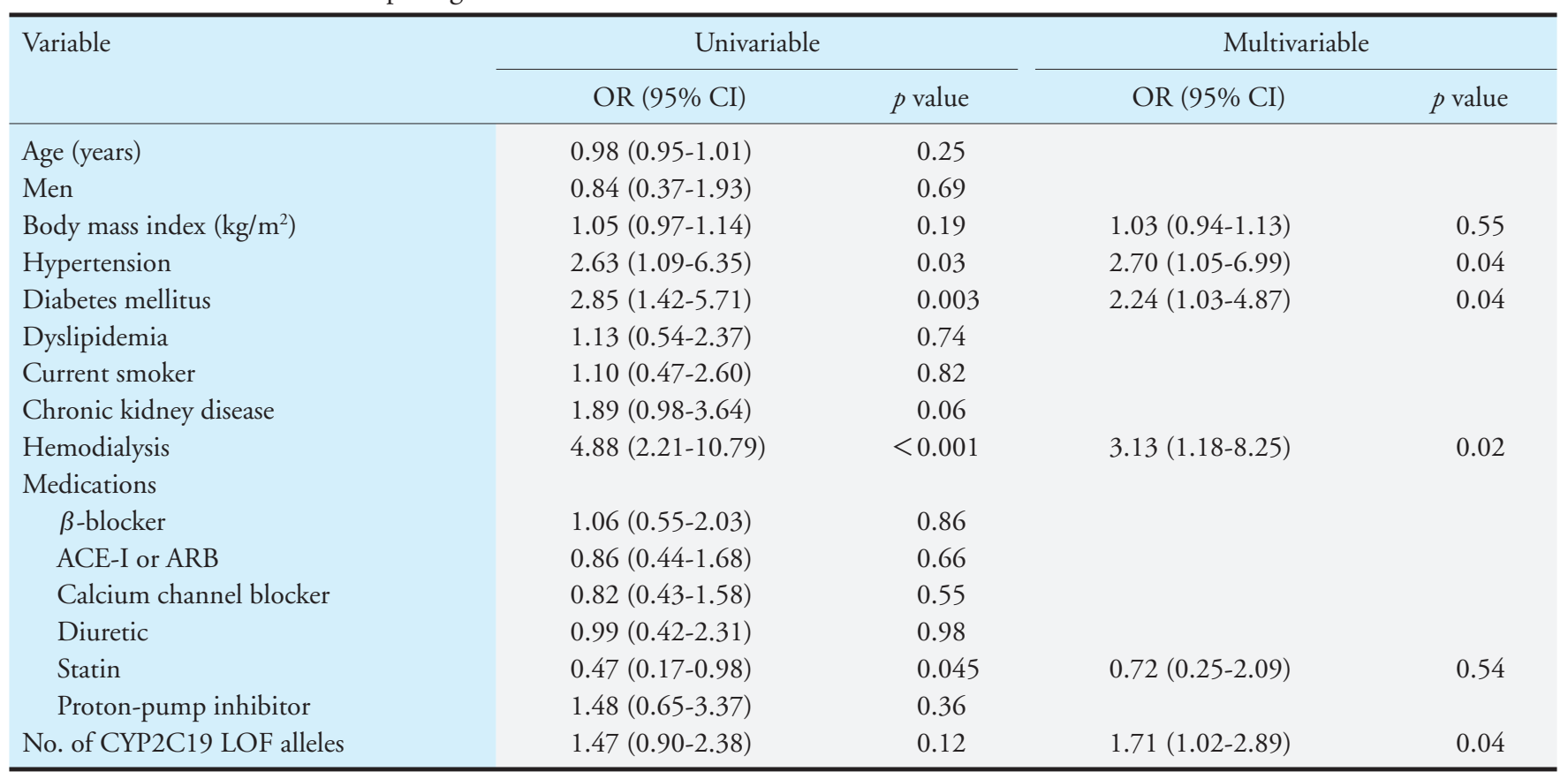

Chronic kidney disease is defined as estimated glomerular filtration rate $\leq 30 \mathrm{ml} / \mathrm{min} / 1.73 \mathrm{~m}^{2}$. ACE-I, angiotensin converting enzyme inhibitor; $\mathrm{ARB}$, angiotensin II receptor blocker; HPR, high platelet reactivity; LOF, loss-of-function.

patients had one or two CYP2C19 LOF alleles (Table 1). Multivariable analysis identified hypertension, diabetes, hemodialysis, and the number of CYP2C19
LOF alleles as factors significantly associated with HPR on prasugrel (Table 2). Based on the odds ratios in multivariable analysis, point values were assigned to

\section{Advance Publication Journal of Atherosclerosis and Thrombosis}




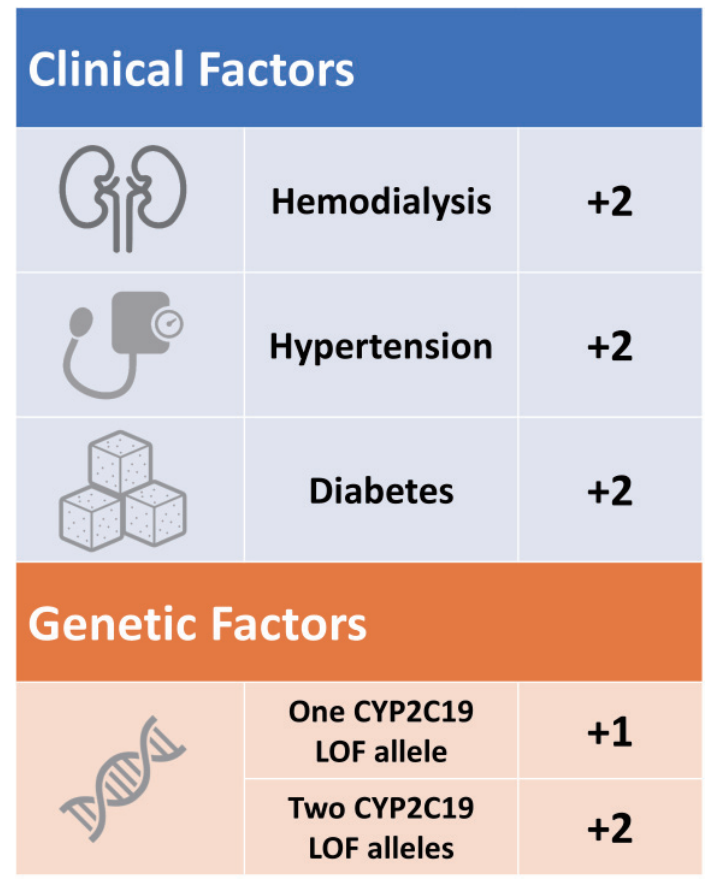

Fig. 1. HHD-GENE score

The HHD-GENE score was developed using four independent predictors of HPR on prasugrel. LOF, loss-of-function.

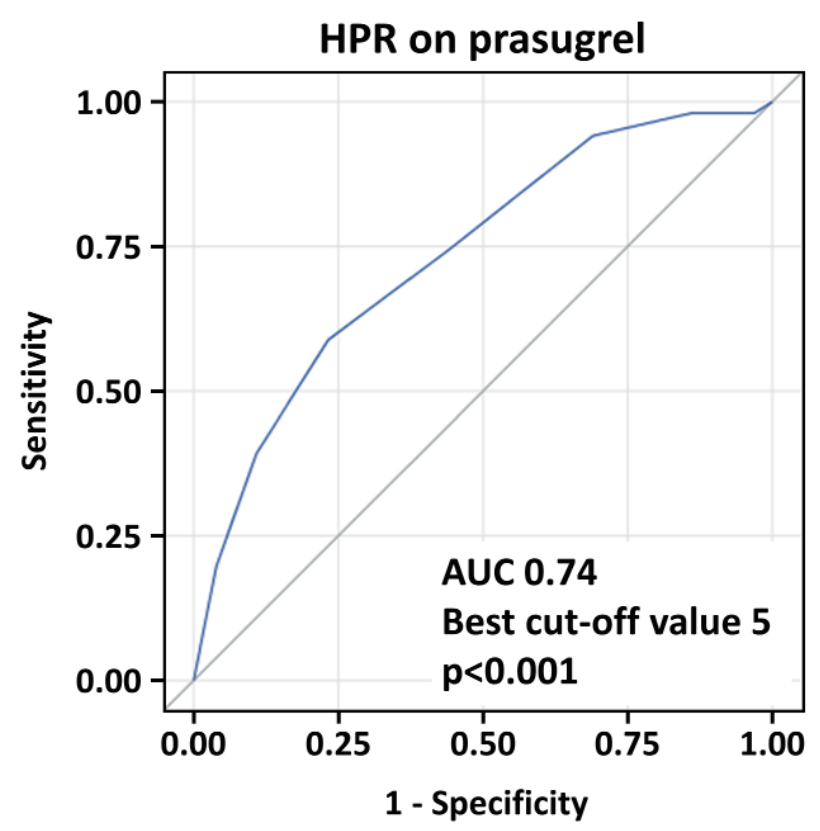

Fig. 2. Receiver operating characteristic curve analysis for HPR on prasugrel

AUC, area under the curve; HPR, high platelet reactivity.

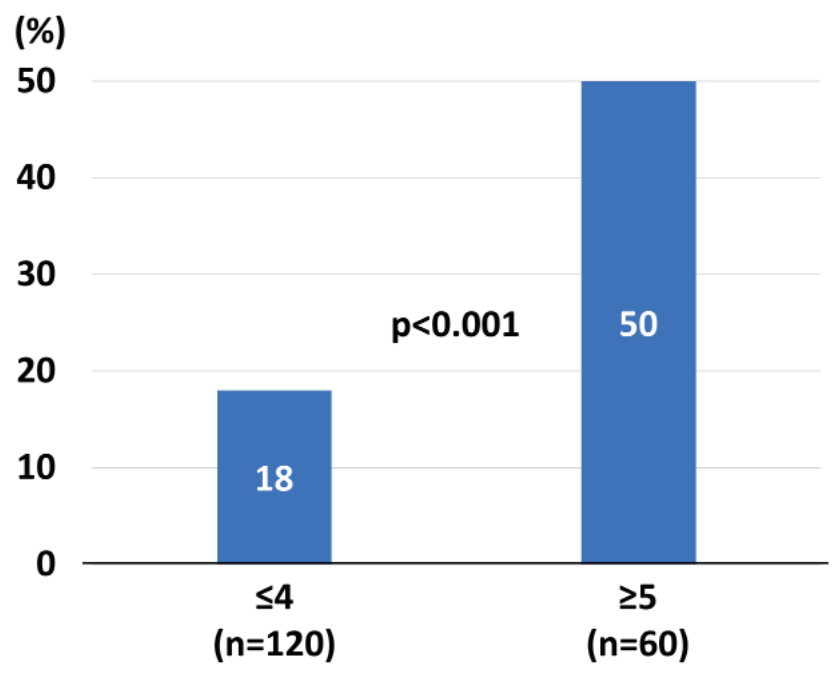

\section{HHD-GENE score}

Fig. 3. Rate of HPR on prasugrel according to the HHD-GENE score HPR, high platelet reactivity.

the factors as shown in Fig. 1 in order to create a risk prediction model for HPR on prasugrel, that is, the HHD-GENE score. In the ROC curve analysis, the HHD-GENE score predicted HPR on prasugrel with the best cutoff value of 5 (AUC 0.74, $p<0.001$ )
(Fig. 2). Patients with the HHD-GENE score $\geq 5$ had a significantly increased risk of HPR on prasugrel than their counterparts (Fig.3). The association between the HHD-GENE score and rates of HPR on prasugrel is shown in Supplementary Fig. 1. The sensitivity,

\section{Advance Publication Journal of Atherosclerosis and Thrombosis}


specificity, positive predictive value, negative predictive value, and accuracy of the HHD-GENE score of 5 were $59 \%, 77 \%, 50 \%, 83 \%$, and $72 \%$, respectively. As a sensitivity analysis, the HHD-GENE score was also able to predict PRU $\geq 262$ on prasugrel (AUC $0.79, p=0.001)$. When only clinical factors (hypertension, diabetes, and hemodialysis) were used for developing a risk prediction model, it also significantly predicted HPR on prasugrel $(p<0.001)$, but its diagnostic ability was inferior to that of the HHD-GENE score (AUC 0.70 vs. 0.74, $p=0.03$ ). How the number of clinical factors affected the rates of HPR on prasugrel is shown in Supplementary Fig. 2.

\section{Discussion}

This present study demonstrated that HPR on prasugrel at a maintenance dose was observed in $28 \%$ of patients in this pooled dataset. Hypertension, diabetes, hemodialysis, and the number of CYP2C19 LOF alleles were identified as factors associated with HPR on prasugrel and were then combined to develop the HHD-GENE score, which had a moderate diagnostic ability for HPR on prasugrel. To the best of our knowledge, this is the first study to propose a risk prediction model for HPR on prasugrel.

\section{Impact of HPR}

HPR, which refers to inadequate platelet inhibition, is frequently observed on clopidogrel and is associated with an increased risk of thrombotic events in patients undergoing PCI. The large-scale ADAPT-DES trial demonstrated that patients with HPR $>208$ had a higher risk of myocardial infarction $(3.9 \%$ vs. $2.7 \%, p=0.01)$ and definite stent thrombosis $(1.0 \%$ vs. $0.4 \%, p<0.001)$ than those with $\mathrm{HPR}<208$ at 1 year after $\mathrm{PCI}^{6}{ }^{6}$. Our previous study clearly showed that HPR was less frequently observed on prasugrel than clopidogrel $(60.3 \%$ vs. $\left.28.3 \%, p<0.001)^{13}, 14\right)$. However, even on prasugrel, HPR is often noted, especially in East Asian patients ${ }^{2)}$. The PENDULUM study, in which more than $60 \%$ of patients received prasugrel as a P2Y12 inhibitor, showed that HPR defined as PRU >208 was significantly associated with an increased risk of ischemic events in patients undergoing contemporary PCI procedures in Japan ${ }^{21)}$, highlighting that HPR remains an important issue in patients treated with clopidogrel and prasugrel in the current $\mathrm{era}^{22,23)}$. Therefore, identification of patients at risk for HPR is clinically relevant.

\section{Factors Associated with HPR}

Several studies have reported factors associated with HPR on P2Y12 inhibitors, such as diabetes, smoking, obesity, inflammation, age, sex, CKD, and genetics $^{7)}$, most of which were investigated on clopidogrel using the ABCD-GENE score ${ }^{8)}$. However, data remain scarce on prasugrel. Indeed, the ABCDGENE score was not predictive for HPR on prasugrel as we showed previously ${ }^{13)}$. In this present study, hypertension, diabetes, hemodialysis, and the number of CYP2C19 LOF alleles were demonstrated as predictors of HPR on prasugrel. The substudy of ADAPT-DES trial showed that the presence of hypertension was associated with a higher likelihood of HPR on clopidogrel $^{24)}$. Given the large sample size and prospective nature of the ADAPT-DES trial, the evidence may be compelling. Diabetes is a well-known factor related to HPR on clopidogrel, and an exploratory analysis from the TROPICAL-ACS trial suggested that diabetes was likely to contribute to HPR on prasugrel assessed with a different assay from VerifyNow ${ }^{25)}$. CKD is another well-known factor for HPR on clopidogrel, but among the patients with CKD, hemodialysis may have a different impact on P2Y12 inhibitor resistance. According to our previous report, clopidogrel reactivity was impacted by stage 3 $\mathrm{CKD}$, whereas prasugrel was not ${ }^{14)}$. However, even on prasugrel, hemodialysis was significantly associated with an increased risk of HPR. Given that patients undergoing hemodialysis were excluded from most of the previous studies, this present finding is important. In terms of genetics, although it has been believed that CYP2C19 variants do not affect inhibition of platelet aggregation in patients treated with prasugrel rather than clopidogrel ${ }^{26)}$, some studies alluded that CYP2C19 genotypes may be associated with platelet inhibition even on prasugrel ${ }^{27)}$. The present and our previous studies provide new data to this literature that CYP2C19 LOF alleles contributed to a higher likelihood of HPR on prasugrel, but the magnitude of genetic variant was smaller in prasugrel compared with that in clopidogrel ${ }^{14)}$. Indeed, the addition of genetic factors into a model improved its diagnostic ability. Taken together, we believe that the clinical and genetic factors included in the HHD-GENE score may be rational, whereas clinical but genetic factors in the HHD-GENE score (i.e., hemodialysis, hypertension, and diabetes) might be helpful in identifying patients with HPR on prasugrel even if genotyping cannot be performed in daily clinical practice (Supplementary Fig. 2).

In this present study, the HHD-GENE score internally had a moderate diagnostic ability for HPR on prasugrel (i.e., AUC: 0.74). The AUCs of ABCDGENE score, a risk model for predicting HPR on clopidogrel, were reported to be 0.71 in the derivation 
cohort and 0.64 in the external validation cohort, respectively ${ }^{8)}$. Given that many risk prediction models (e.g., $\mathrm{CHADS}_{2}$ score) have been used to aid in decision-making in daily practice with modest diagnostic ability ${ }^{28)}$, the HHD-GENE score may be deemed clinically useful. In case a patient has HHDGENE score $\geq 5$, prasugrel treatment may often result in HPR, but at the same time, clopidogrel is likely to pose HPR for the patient. In this scenario, ticagrelor may be an alternative to avoid HPR. We and others have reported that ticagrelor provided more potent platelet inhibition than prasugrel ${ }^{29,30)}$. In our previous report, PRU values were significantly lower in patients treated with $60 \mathrm{mg}$ of ticagrelor twice daily than those treated with $3.5 \mathrm{mg}$ of prasugrel once daily, and no patients had HPR on ticagrelor in Japanese patients with prior myocardial infarction ${ }^{30)}$. Although antithrombotic therapy was used to mitigate thrombotic risks, their use must be balanced against bleeding complications; potent antiplatelet therapy under a risk score guidance presumably has a potential to improve clinical outcomes.

\section{Study Limitations}

This present study has several limitations. The four studies included into the current analysis were prospective, but the pooled dataset was evaluated as a post hoc analysis. Given the relatively small sample size, some factors reportedly associated with HPR (e.g., female sex) may have been neglected ${ }^{31)}$. Due to the design of the original studies (i.e., short follow-up period to evaluate PRU values and genotype), clinical outcomes were not available. In addition, polymorphism in CYP3A4, CYP2B6, and CYP2C9 as well as CYP2C19 may be associated with poor metabolism of prasugrel, but only genotyping of CYP2C19 was performed in this present study ${ }^{32,33)}$. Although a cutoff value of 208 was used for defining HPR in this present study according to the recent consensus statement ${ }^{7)}$, different thresholds may be deemed applicable. However, as a sensitivity analysis, PRU $\geq 262$ on prasugrel was also tested and showed similar results in this study. Because of the lack of external validation of the HHD-GENE score, this present study should be considered as the generation of a hypothesis, and further studies with a large sample size are needed.

\section{Conclusions}

The HHD-GENE score, consisting of hypertension, diabetes, hemodialysis, and CYP2C19 LOF alleles, is a simple tool that has the potential to evaluate patients at a high risk for HPR on prasugrel.
External validation is warranted to define its clinical utility.

\section{Disclosures}

Yoshio Kobayashi reports research grants from Daiichi Sankyo. Other authors declare nothing to disclose.

\section{References}

1) Valgimigli M, Bueno H, Byrne RA, Collet JP, Costa F, Jeppsson A, Jüni P, Kastrati A, Kolh P, Mauri L, Montalescot G, Neumann FJ, Petricevic M, Roffi M, Steg PG, Windecker S, Zamorano JL, Levine GN; ESC Scientific Document Group; ESC Committee for Practice Guidelines (CPG); ESC National Cardiac Societies. 2017 ESC focused update on dual antiplatelet therapy in coronary artery disease developed in collaboration with EACTS: The Task Force for dual antiplatelet therapy in coronary artery disease of the European Society of Cardiology (ESC) and of the European Association for Cardio-Thoracic Surgery (EACTS). Eur Heart J, 2018; 39: 213-260

2) Saito Y, Kobayashi Y, Tanabe K, Ikari Y. Antithrombotic therapy after percutaneous coronary intervention from the Japanese perspective. Cardiovasc Interv Ther, 2020; 35: 19-29

3) Saito Y, Kobayashi Y. Update on Antithrombotic Therapy after Percutaneous Coronary Intervention. Intern Med, 2020; 59: 311-321

4) Schüpke S, Neumann FJ, Menichelli M, Mayer K, Bernlochner I, Wöhrle J, Richardt G, Liebetrau C, Witzenbichler B, Antoniucci D, Akin I, Bott-Flügel L, Fischer M, Landmesser U, Katus HA, Sibbing D, Seyfarth M, Janisch M, Boncompagni D, Hilz R, Rottbauer W, Okrojek R, Möllmann H, Hochholzer W, Migliorini A, Cassese S, Mollo P, Xhepa E, Kufner S, Strehle A, Leggewie S, Allali A, Ndrepepa G, Schühlen H, Angiolillo DJ, Hamm CW, Hapfelmeier A, Tölg R, Trenk D, Schunkert H, Laugwitz KL, Kastrati A; ISAR-REACT 5 Trial Investigators. Ticagrelor or Prasugrel in Patients with Acute Coronary Syndromes. N Engl J Med, 2019; 381: 1524-1534

5) Collet JP, Thiele H, Barbato E, Barthélémy O, Bauersachs J, Bhatt DL, Dendale P, Dorobantu M, Edvardsen T, Folliguet T, Gale CP, Gilard M, Jobs A, Jüni P, Lambrinou E, Lewis BS, Mehilli J, Meliga E, Merkely B, Mueller C, Roffi M, Rutten FH, Sibbing D, Siontis GCM; ESC Scientific Document Group. 2020 ESC Guidelines for the management of acute coronary syndromes in patients presenting without persistent ST-segment elevation. Eur Heart J, 2021; 42: 1289-1367

6) Stone GW, Witzenbichler B, Weisz G, Rinaldi MJ, Neumann FJ, Metzger DC, Henry TD, Cox DA, Duffy PL, Mazzaferri E, Gurbel PA, Xu K, Parise H, Kirtane AJ, Brodie BR, Mehran R, Stuckey TD; ADAPT-DES Investigators. Platelet reactivity and clinical outcomes after coronary artery implantation of drug-eluting stents

\section{Advance Publication Journal of Atherosclerosis and Thrombosis}


(ADAPT-DES): a prospective multicentre registry study. Lancet, 2013; 382: 614-623

7) Sibbing D, Aradi D, Alexopoulos D, Ten Berg J, Bhatt DL, Bonello L, Collet JP, Cuisset T, Franchi F, Gross L, Gurbel P, Jeong YH, Mehran R, Moliterno DJ, Neumann FJ, Pereira NL, Price MJ, Sabatine MS, So DYF, Stone GW, Storey RF, Tantry U, Trenk D, Valgimigli M, Waksman R, Angiolillo DJ. Updated Expert Consensus Statement on Platelet Function and Genetic Testing for Guiding P2Y12 Receptor Inhibitor Treatment in Percutaneous Coronary Intervention. JACC Cardiovasc Interv, 2019; 12: 1521-1537

8) Angiolillo DJ, Capodanno D, Danchin N, Simon T, Bergmeijer TO, Ten Berg JM, Sibbing D, Price MJ. Derivation, Validation, and Prognostic Utility of a Prediction Rule for Nonresponse to Clopidogrel: The ABCD-GENE Score. JACC Cardiovasc Interv, 2020; 13: 606-617

9) Nishi T, Ariyoshi N, Nakayama T, Fujimoto Y, Sugimoto K, Takahara M, Wakabayashi S, Koshizaka M, Hanaoka $\mathrm{H}$, Kobayashi Y. Increased platelet inhibition after switching from maintenance clopidogrel to prasugrel in Japanese patients with stable coronary artery disease. Circ J, 2015; 79: 2439-2444

10) Ohno Y, Kitahara H, Fujii K, Kohno Y, Ariyoshi N, Nishi T, Fujimoto Y, Kobayashi Y. High residual platelet reactivity after switching from clopidogrel to low-dose prasugrel in Japanese patients with end-stage renal disease on hemodialysis. J Cardiol, 2019; 73: 51-57

11) Wakabayashi S, Ariyoshi N, Kitahara H, Fujii K, Fujimoto Y, Kobayashi Y. Efficacy of 2.5-mg Prasugrel in Elderly or Low-Body-Weight Patients. Circ J, 2018; 82: 2326-2331

12) Wakabayashi $S$, Kitahara $H$, Nishi $T$, Sugimoto $K$, Nakayama T, Fujimoto Y, Ariyoshi N, Kobayashi Y. Platelet inhibition after loading dose of prasugrel in patients with ST-elevation and non-ST-elevation acute coronary syndrome. Cardiovasc Interv Ther, 2018; 33: $239-246$

13) Saito Y, Nishi T, Wakabayashi S, Ohno Y, Kitahara H, Ariyoshi N, Kobayashi Y. Validation of the ABCD-GENE score to identify high platelet reactivity in east Asian patients undergoing percutaneous coronary intervention. Int J Cardiol, 2021; 327: 15-18

14) Saito Y, Nishi T, Wakabayashi S, Ohno Y, Kitahara H, Ariyoshi N, Kobayashi Y. Differential Impact of Clinical and Genetic Factors on High Platelet Reactivity in Patients with Coronary Artery Disease Treated with Clopidogrel and Prasugrel. J Atheroscler Thromb, 2021. doi: $10.5551 /$ jat.63035

15) Saito Y, Kobayashi Y, Fujii K, Sonoda S, Tsujita K, Hibi K, Morino Y, Okura H, Ikari Y, Honye J. Clinical expert consensus document on standards for measurements and assessment of intravascular ultrasound from the Japanese Association of Cardiovascular Intervention and Therapeutics. Cardiovasc Interv Ther, 2020; 35: 1-12

16) Sonoda S, Hibi K, Okura H, Fujii K, Honda Y, Kobayashi Y. Current clinical use of intravascular ultrasound imaging to guide percutaneous coronary interventions. Cardiovasc Interv Ther, 2020; 35: 30-36

17) Kurogi K, Ishii M, Yamamoto N, Yamanaga K, Tsujita K.
Optical coherence tomography-guided percutaneous coronary intervention: a review of current clinical applications. Cardiovasc Interv Ther, 2021; 36: 169-177

18) Saito Y, Kobayashi Y. Contemporary coronary drugeluting and coated stents: a mini-review. Cardiovasc Interv Ther, 2021; 36: 20-22

19) Kimura T, Isshiki T, Ogawa $H$, Yokoi $H$, Yamaguchi $T$, Ikeda Y. Randomized, Double-Blind, Dose-Finding, Phase II Study of Prasugrel in Japanese Patients Undergoing Elective Percutaneous Coronary Intervention. J Atheroscler Thromb, 2015; 22: 557-569

20) Nakamura $M$, Isshiki $T$, Kimura $T$, Ogawa $H$, Yokoi $H$, Nanto S, Takayama M, Kitagawa K, Ikeda Y, Saito S. Optimal cutoff value of P2Y12 reaction units to prevent major adverse cardiovascular events in the acute periprocedural period: post-hoc analysis of the randomized PRASFIT-ACS study. Int J Cardiol, 2015; 182: $541-548$

21) Nakamura M, Kadota K, Takahashi A, Kanda J, Anzai H, Ishii Y, Shibata Y, Yasaka Y, Takamisawa I, Yamaguchi J, Takeda Y, Harada A, Motohashi T, Iijima R, Uemura S, Murakami Y; PENDULUM Registry Investigators. Relationship Between Platelet Reactivity and Ischemic and Bleeding Events After Percutaneous Coronary Intervention in East Asian Patients: 1-Year Results of the PENDULUM Registry. J Am Heart Assoc, 2020; 9: e015439

22) Kuramitsu S, Sonoda S, Ando K, Otake H, Natsuaki M, Anai R, Honda Y, Kadota K, Kobayashi Y, Kimura T. Drug-eluting stent thrombosis: current and future perspectives. Cardiovasc Interv Ther, 2021; 36: 158-168

23) Sakamoto K, Sato R, Tabata N, Ishii M, Yamashita T, Nagamatsu S, Motozato K, Yamanaga K, Hokimoto S, Sueta D, Araki S, Fujisue K, Arima Y, Takashio S, Fujimoto K, Shimomura H, Tsunoda R, Hirose T, Sato K, Kikuta K, Sakaino N, Nakamura S, Yamamoto N, Matsumura T, Kajiwara I, Tayama S, Sakamoto T, Nakao K, Oshima S, Yamamoto E, Kaikita K, Tsujita K; Kumamoto Intervention Conference Study (KICS) Investigators. Temporal trends in coronary intervention strategies and the impact on one-year clinical events: data from a Japanese multi-center real-world cohort study. Cardiovasc Interv Ther, 2021. doi: 10.1007/s12928-02000752-5

24) Redfors B, Chen S, Ben-Yehuda O, Huang $X$, Witzenbichler B, Weisz G, Liu Y, Brodie BR, Rinaldi MJ, Neumann FJ, Metzger DC, Henry TD, Cox DA, Duffy PL, Mazzaferri EL Jr, Mehran R, Stuckey TD, Kirtane AJ, Stone GW. Association Between Hypertension, Platelet Reactivity, and the Risk of Adverse Events After Percutaneous Coronary Intervention (From the ADAPTDES Study). Am J Cardiol, 2019; 124: 1380-1388

25) Aradi D, Gross L, Trenk D, Geisler T, Merkely B, Kiss RG, Komócsi A, Dézsi CA, Ruzsa Z, Ungi I, Rizas KD, May AE, Mügge A, Zeiher AM, Holdt L, Huber K, Neumann FJ, Koltowski L, Huczek Z, Hadamitzky M, Massberg S, Sibbing D. Platelet reactivity and clinical outcomes in acute coronary syndrome patients treated with prasugrel and clopidogrel: a pre-specified exploratory analysis from the TROPICAL-ACS trial. Eur Heart J, 2019; 40: 1942-1951

\section{Advance Publication Journal of Atherosclerosis and Thrombosis


26) Mega JL, Close SL, Wiviott SD, Shen L, Hockett RD, Brandt JT, Walker JR, Antman EM, Macias WL, Braunwald E, Sabatine MS. Cytochrome P450 genetic polymorphisms and the response to prasugrel: relationship to pharmacokinetic, pharmacodynamic, and clinical outcomes. Circulation, 2009; 119: 2553-2560

27) Grosdidier C, Quilici J, Loosveld M, Camoin L, Moro PJ, Saut N, Gaborit B, Pankert M, Cohen W, Lambert M, Beguin S, Morange PE, Bonnet JL, Alessi MC, Cuisset T. Effect of CYP2C19*2 and * 17 genetic variants on platelet response to clopidogrel and prasugrel maintenance dose and relation to bleeding complications. Am J Cardiol, 2013; 111: 985-990

28) van den Ham HA, Klungel OH, Singer DE, Leufkens HG, van Staa TP. Comparative Performance of ATRIA, CHADS2, and CHA2DS2-VASc Risk Scores Predicting Stroke in Patients With Atrial Fibrillation: Results From a National Primary Care Database. J Am Coll Cardiol, 2015; 66: 1851-1819

29) Alexopoulos D, Galati A, Xanthopoulou I, Mavronasiou E, Kassimis G, Theodoropoulos KC, Makris G, Damelou A, Tsigkas G, Hahalis G, Davlouros P. Ticagrelor versus prasugrel in acute coronary syndrome patients with high on-clopidogrel platelet reactivity following percutaneous coronary intervention: a pharmacodynamic study. J Am Coll Cardiol, 2012; 60: 193-199
30) Tateishi K, Saito Y, Kitahara H, Nakayama T, Fujimoto Y, Kobayashi Y. Increased platelet inhibition after switching from prasugrel to low-dose ticagrelor in Japanese patients with prior myocardial infarction. J Cardiol, 2020; 75: 473-477

31) Yu J, Mehran R, Baber U, Ooi SY, Witzenbichler B, Weisz G, Rinaldi MJ, Neumann FJ, Metzger DC, Henry TD, Cox DA, Duffy PL, Mazzaferri EL Jr, Brodie BR, Stuckey TD, Maehara A, Xu K, Ben-Yehuda O, Kirtane AJ, Stone GW. Sex Differences in the Clinical Impact of High Platelet Reactivity After Percutaneous Coronary Intervention With Drug-Eluting Stents: Results From the ADAPT-DES Study (Assessment of Dual Antiplatelet Therapy With Drug-Eluting Stents). Circ Cardiovasc Interv, 2017; 10: e003577

32) Rehmel JL, Eckstein JA, Farid NA, Heim JB, Kasper SC, Kurihara A, Wrighton SA, Ring BJ. Interactions of two major metabolites of prasugrel, a thienopyridine antiplatelet agent, with the cytochromes P450. Drug Metab Dispos, 2006; 34: 600-607

33) Yamagata Y, Koga S, Ikeda S, Maemura K. Acute thrombosis of everolimus-eluting platinum chromium stent caused by impaired prasugrel metabolism due to cytochrome P450 enzyme 2B6*2 (C64T) polymorphism: a case report. Eur Heart J Case Rep, 2020; 4: 1-7 
Supplementary Table 1. Four studies investigating PRU values and genotypes

\begin{tabular}{|c|c|c|c|c|}
\hline & Study \#1 & Study \#2 & Study \#3 & Study \#4 \\
\hline Registration No. & UMIN000014528 & UMIN000022139 & UMIN000019424 & UMIN000017547 \\
\hline Population & Non-specific CCS & Hemodialysis & Age $\geq 75$ y or $\mathrm{BW}<50 \mathrm{~kg}$ & Non-specific ACS \\
\hline Major exclusion criteria & $\begin{array}{c}\text { Age }>80 \mathrm{y}, \mathrm{BW} \leq 50 \mathrm{~kg} \text {, } \\
\text { Renal dysfunction }\end{array}$ & Age $>80 y, B W \leq 50 \mathrm{~kg}$ & Hemodialysis & $\begin{array}{c}\text { Age }>85 \mathrm{y}, \mathrm{BW} \leq 45 \mathrm{~kg} \text {, } \\
\text { Renal dysfunction }\end{array}$ \\
\hline
\end{tabular}

Renal dysfunction is defined as estimated glomerular filtration rate $\leq 30 \mathrm{ml} / \mathrm{min} / 1.73 \mathrm{~m}^{2}$. $^{\dagger}$ Four patients were excluded because of the lack of PRU measurement. 'All PRU measurement was performed at maintenance dose of prasugrel (3.75 mg daily). ACS, acute coronary syndrome; BW, body weight; CCS, chronic coronary syndrome; PRU, platelet reactivity unit; UMIN, University Hospital Medical Information Network.

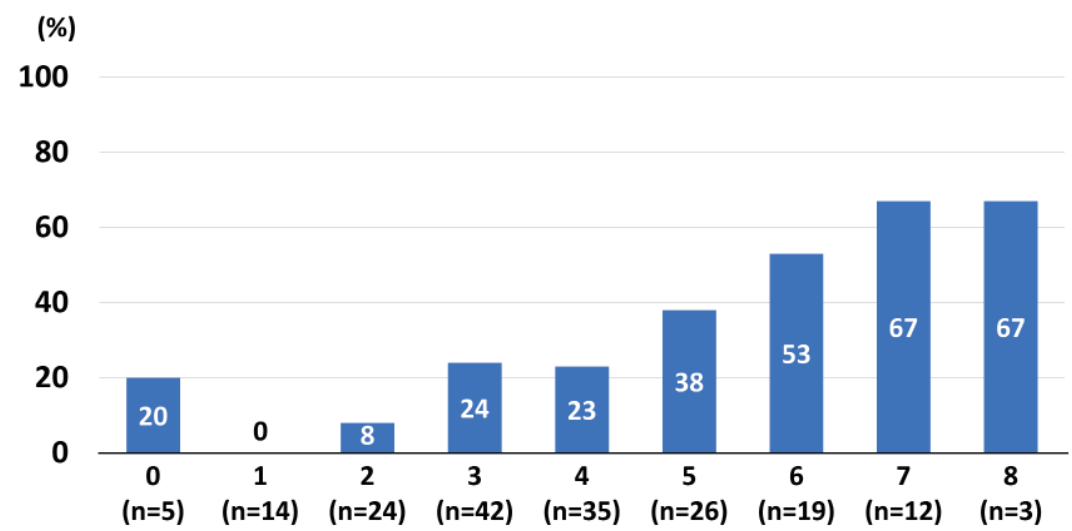

Supplementary Fig. 1. Rate of HPR on prasugrel according to the HHD-GENE score

HPR, high platelet reactivity.

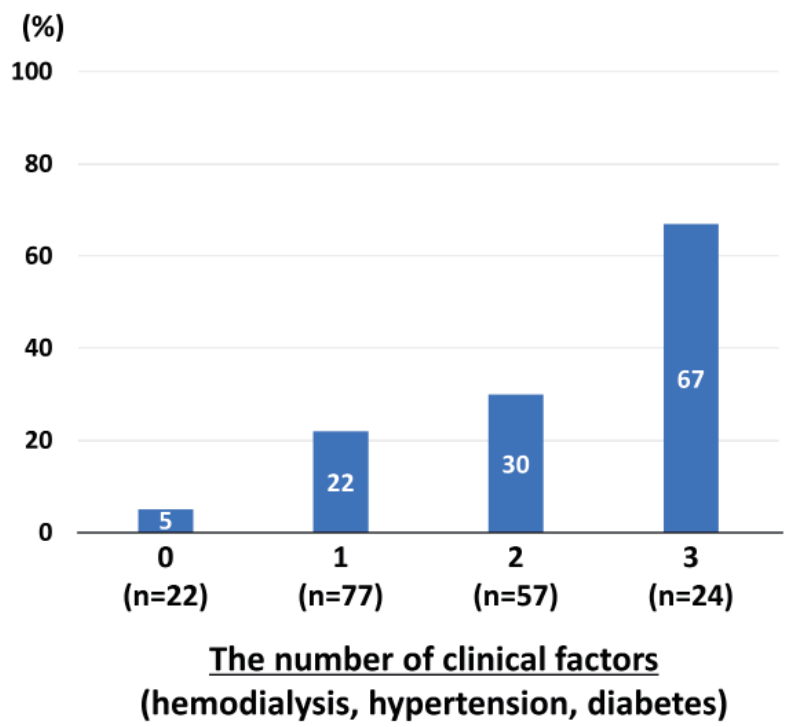

Supplementary Fig. 2. Rate of HPR on prasugrel according to the HHD-GENE score based on the number of clinical factors $\mathrm{HPR}$, high platelet reactivity.

\section{Advance Publication Journal of Atherosclerosis and Thrombosis}

